\title{
Ramadan fasting and type 1 diabetes: on a case successfully managed with an integrated system based on predictive low-glucose suspend algorithm
}

\author{
Marina Valenzano $^{1}$ (D) Elena Gamarra ${ }^{1,2} \cdot$ Giorgio Grassi $^{1}$
}

Received: 23 December 2020 / Accepted: 22 February 2021 / Published online: 8 March 2021

(c) The Author(s) 2021

Keywords Type 1 Diabetes · Ramadan · Fasting · Predictive low-glucose suspend algorithm · Pump therapy · Integrated systems for insulin delivery

\section{Introduction}

The number of Muslim people with diabetes is expected to increase also in Western Countries [1]. Performing Ramadan fasting is a strong desire for many Muslim patients despite diabetes; in fact, a large epidemiological study [2] in the early 2000s confirmed that a consistent number of them, both with type 1 and type 2 diabetes, try to fast for several days, often without proper medical supervision, which may lead to complications like hypoglycaemia, hyperglycaemia, ketoacidosis, dehydration and thrombosis. International guidelines [1] provide healthcare professionals with the information needed to select patients who should avoid fasting because of excessive health risk and to support those who persist with their decision to fast. However, scarce evidence is available regarding the application of new technologies for diabetes care in this specific subset. A recent systematic review and meta-analysis about safety of Ramadan fasting in type 1 diabetes [3] suggests that fine-tuning of insulin therapy by the use of pump infusion and intensive glucose control may mitigate hypoglycaemia risk. Further, an observational study has compared sensor-augmented pump therapy (SAP), equipped with a low-glucose suspend

Communicated by Antonio Secchi .

Marina Valenzano

valenzano.marina@gmail.com

1 Division of Endocrinology, Diabetes and Metabolic Diseases, Department of Medical Sciences, University of Turin, A.O.U. Città della Salute e della Scienza - Le Molinette Hospital, Corso Bramante 88, 10126 Turin, Italy

2 Present Address: Clinique Et Centre Médical Thérapeutique La Lignière, 1196 Gland, Switzerland
(LGS) function, to traditional continuous insulin infusion in association with continuous glucose monitoring (CGM) and no automatic suspension [4]. Although the SAP system mentioned above proved to be safe and to reduce both hypoand hyper-glycaemic excursions, it has now been replaced by more advanced models and is no longer commercialised. Finally, there is no consensus regarding manual insulin dose adjustments, while substantial evidence is still lacking on the use of automatic insulin delivery to the specific setting of Ramadan, except for a single report on a hybrid closedloop system.

We here report the case of a patient with type 1 diabetes who, because of several severe hypoglycaemic episodes, had previously failed to fast during Ramadan and who volunteered to pursue a new attempt using advanced technologies for diabetes care.

\section{Case history}

A 20-year-old young Italian woman of Egyptian origin (body mass index $25 \mathrm{~kg} / \mathrm{m}^{2}$ ) wished to fast during Ramadan. She was affected by type 1 diabetes since the age of 3 , treated with multiple daily insulin injections. The patient showed no chronic complications and no comorbidities, except for autoimmune thyroid disease with no need for replacement therapy. Her glucose control had always been close to target (HbA1c 53-59 $\mathrm{mmol} / \mathrm{mol}$, 7-7.5\%), with no episodes of ketoacidosis or severe hypoglycaemia. Latest daily insulin requirement was $61 \mathrm{IU}$ (e.g. $0.9 \mathrm{IU} / \mathrm{kg} / \mathrm{die}$ ), consisting of $41 \%$ basal insulin and 59\% boluses. The patient was instructed about carbohydrate counting. As mentioned, the patient had previously unsuccessfully attempted to fast during Ramadan but several 
hypoglycaemic episodes forced her to interrupt. During the last attempt, she experienced worsening of metabolic control (HbA1c up to $75 \mathrm{mmol} / \mathrm{mol}, 9.0 \%$ ). The patient was willing to use diabetes treatment technologies to try Ramadan fasting again.

\section{Intervention}

In February 2020, the patient started pump therapy with integrated continuous glucose monitoring.

The integrated system consisted of the Basal-IQ ${ }^{\circledR}$ technology on the t:slim X2 ${ }^{\mathrm{TM}}$ pump (Tandem Diabetes Care Inc., San Diego, California), based on a predictive lowglucose suspend algorithm (PLGS). Thanks to the PLGS function, insulin delivery is temporarily blocked whenever sensor-glucose is expected to become lower than $80 \mathrm{mg} /$ $\mathrm{dl}(4.4 \mathrm{mmol} / \mathrm{L})$ in the following $30 \mathrm{~min}$. Interruption of delivery may last for a maximum of $2 \mathrm{~h}$ in a 2.5-h window and is automatically resumed as soon as glucose trend reverts.

Then, according to the IDF-DAR [1] and Italian guidelines, the patient was assigned to a moderate risk category and therefore allowed to fast. In April 2020, she received special education regarding diet counselling and self-monitoring of glucose. Her pump was set up with a tailored basal insulin profile: insulin basal rate was reduced by $38 \%$ in the last $4 \mathrm{~h}$ of fasting (corresponding to a $14 \%$ reduction in morning daily dose), as recommended in [1]. The nocturnal settings, insulin sensitivity factor and insulin/ carbohydrates (I/CHO) ratios were left unchanged. To further decrease the risk of hypoglycaemia due to aggressive corrections, optimal glycaemic target for bolus calculator was increased by $12.5 \%$.

\section{Outcome}

The patient achieved optimal glucose control before Ramadan: mean glucose (MG) $145+45 \mathrm{mg} / \mathrm{dl}$ $(8.1+2.5 \mathrm{mmol} / \mathrm{L})($ mean $+\mathrm{SD})$, coefficient of glucose variability $(\mathrm{CV}) 32 \%$, time in target range $70-180 \mathrm{mg} / \mathrm{dl}$ (3.9-10.0 $\mathrm{mmol} / \mathrm{L}$ ) (TIR) $78 \%$, time below target range (TBR) 2\%, time above target range (TAR) 20\%, glucose management indicator (GMI) $49.7 \mathrm{mmol} / \mathrm{mol}$ or $6.7 \%$. The last 14-day ambulatory glucose profile is shown in Fig. 1. The patient started fasting on April 24th 2020 and stopped on May 14th, exempted because of her menstrual cycle. The patient was allowed to eat dates and typical Egyptian food during Iftar and Suhoor (meals taken after sunset and before dawn, respectively) and practised some physical exercise between the two meals, with a daily carbohydrate intake of $179 \pm 59 \mathrm{~g}$. Notably, the patient never had to interrupt daytime fasting because of low glucose values. At the end of her Ramadan fasting, glucose control was still in safe ranges: MG $170 \pm 54 \mathrm{mg} / \mathrm{dl}(9.4+3.0 \mathrm{mmol} / \mathrm{L})$, CV 32\%, TIR 60\%, TBR 1\%, TAR 39\%, GMI $58.5 \mathrm{mmol} /$ mol or $7.5 \%$. The ambulatory glucose profile of the whole fasting period is shown in Fig. 2. Low glucose values were infrequent and clinically mild (never lower than $54 \mathrm{mg} / \mathrm{dl}$ (3.0 $\mathrm{mmol} / \mathrm{L})$ or requiring assistance from bystanders). The predictive algorithm worked through targeted insulin suspensions: $3.7+2.8$ suspension events/day, corresponding to $61 \pm 42 \mathrm{~min} /$ day, preferentially occurring during afternoon and early evening (27\% suspension events occurred in only $4 \mathrm{~h}$, from 2:00 to 6:00 pm). Although basal rates and the $\mathrm{I} / \mathrm{CHO}$ ratios were progressively tuned according to the physician's advice, a tendency towards hyperglycaemia was observed especially after both Iftar and Suhoor meals, with mean glucose values $187+49 \mathrm{mg} /$
Fig.1 Ambulatory glucose profile showing 24-h glucose overlay of the last 14 days before Ramadan fasting (graphical elaboration by DiasendGlooko®, Glooko Inc, Palo Alto, California)

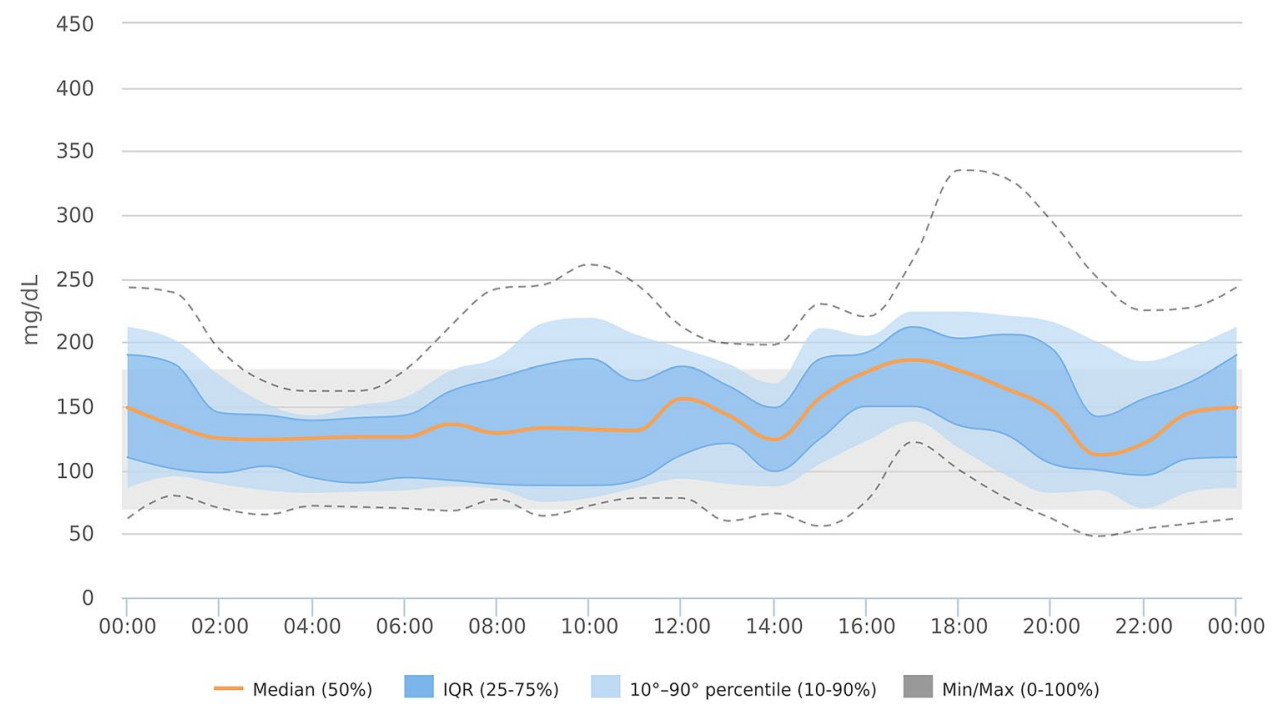


Fig.2 Ambulatory glucose profile showing 24-h glucose overlay during Ramadan (graphical elaboration by Diasend-Glooko®, Glooko Inc, Palo Alto, California)

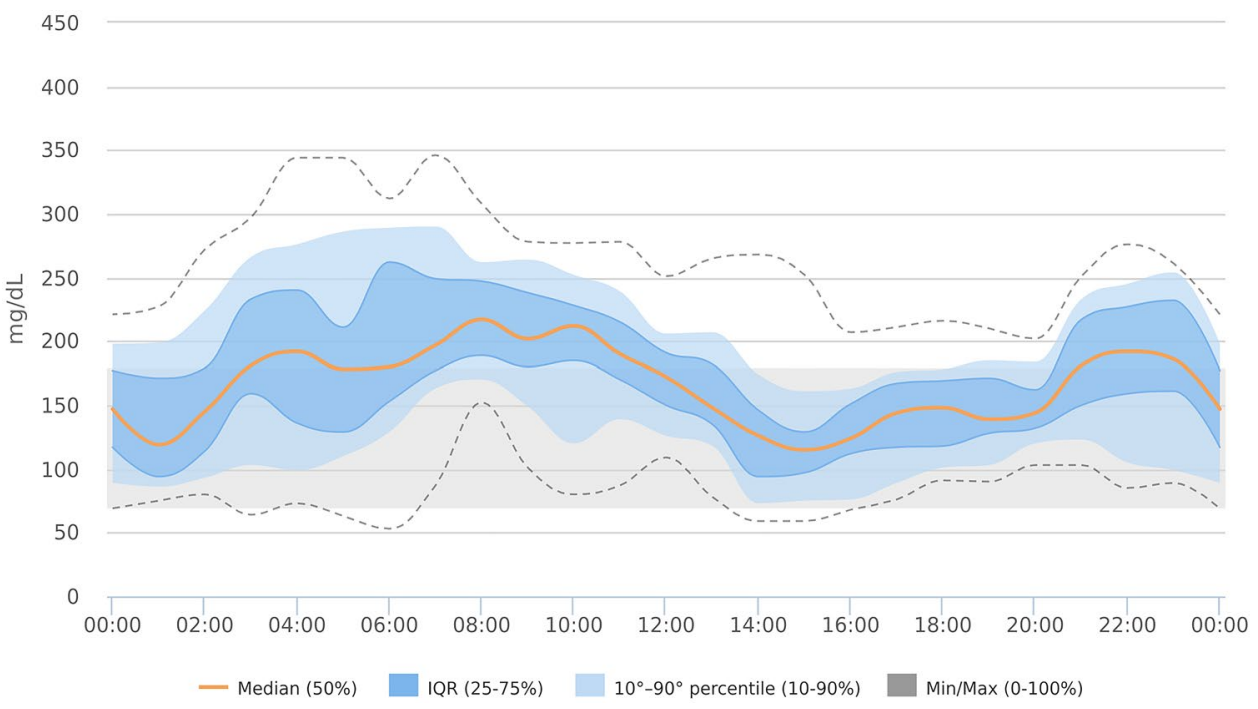

dl $(10.4+2.7 \mathrm{mmol} / \mathrm{L})$ from $10: 00$ to $12: 00 \mathrm{pm}$, and $209+50 \mathrm{mg} / \mathrm{dl}(11.6+2.8 \mathrm{mmol} / \mathrm{L})$ from $6: 00$ to $10: 00$ am. Ketones in capillary blood were self-measured and found in the low-normal range. Finally, during Ramadan, a $40 \%$ reduction in daily insulin dose was observed with a total need of $37 \mathrm{IU}$ (e.g. $0.55 \mathrm{IU} / \mathrm{kg}$ ), 54\% basal insulin and $46 \%$ boluses. In fact, such a continuous therapy modulation led to an extra basal rate decrease in the morning hours, with an overall $25 \%$ reduction in the pre-Ramadan dose. Conversely, nocturnal basal rates increased by $13 \%$, with the most significant modification concerning the first $3 \mathrm{~h}$ following Iftar (36\% increase) and $2 \mathrm{~h}$ after Suhoor (10\% increase).

The patient's satisfaction was assessed at the end of the fasting period by the eight item-based Diabetes Treatment Satisfaction Questionnaire (DTSQ) (score range 1-6 for each item for a total range of 8-48) [5]. The score was 34, well above the expected value of 21 , higher scores referring to treatment flexibility, expanded knowledge of diabetes and propensity to recommend the same treatment to other patients with diabetes willing to observe Ramadan fasting. Overall, the patient defined herself gratified and self-confident.

\section{Discussion}

Managing the Ramadan fasting is challenging for insulintreated patients. New technologies help address this problem, although the quick turn over of devices with advancement of functions and the small body of available evidence have not allowed the editing of full guidance, so far. We here present the case of a young woman with type 1 diabetes with a previous failure of Ramadan fasting who pursued a new attempt using a device based on PLGS algorithm.
Self-management of disease was satisfactory before fasting and still in safe ranges at the end of the experience, with the patient feeling overall gratified.

Compared to a previous work [4], we observed similar results in terms of low-glucose episodes and insulin suspension process, although a different device (with a PLGS algorithm instead of LGS), which limited the patient's workload implying neither suspension alerts nor requests for sensorcalibrations, was used.

Insulin doses were initially adjusted according to international guidelines but required further modulation, finally leading to a therapeutic programme that was closer to previously suggested settings for the use of different technology [4]. Conversely, an inversion of the basal/boluses proportion was observed as a possible consequence of the prudent strategy adopted, both by the patient and by the physician, aimed at preventing hypoglycaemia. It is likely that this approach also underlies some of the modest worsening of nocturnal hyperglycaemia and eventually of the HbAlc value, shown by our patient.

In all, we believe that our experience delivers further confidence in the use of automated technology provided that careful medical supervision is guaranteed alongside timely and informed patient interventions.

\section{Conclusions}

Since prolonged fasting and sudden shift in mealtimes may lead to acute complications, management of glucose control during Ramadan is challenging and requires caution. The experience we report here suggests that, in well-instructed and strongly motivated patients observing Ramadan fasting, technology may greatly limit the risk of hypoglycaemia, while helping to achieve fair glucose control, reduce insulin 
doses and provide empowerment and satisfaction. It is conceivable that progress in diabetes treatment technologies will soon allow even more flexible and personalised therapeutic approaches, thus making Ramadan fasting more easily feasible for people with diabetes.

Authors contribution All authors contributed equally to the clinical management of the case. MV wrote the first draught of the manuscript, and all authors commented on the previous versions of the manuscript. All authors read and approved the final manuscript.

Funding Open access funding provided by Università degli Studi di Torino within the CRUI-CARE Agreement.

Code availability Not applicable.

\section{Compliance with ethical standards}

Conflict of interest The authors declare they have no financial interests.

Availability of data and material Not applicable.

Ethical approval All procedures were performed in accordance with the local ethical standards and with the 1964 Helsinki Declaration and its later amendments.

Consent to participate Informed consent was obtained from the patient.

Consent for publication The participant has consented to the submission of the case report to the journal.

Open Access This article is licensed under a Creative Commons Attribution 4.0 International License, which permits use, sharing, adaptation, distribution and reproduction in any medium or format, as long as you give appropriate credit to the original author(s) and the source, provide a link to the Creative Commons licence, and indicate if changes were made. The images or other third party material in this article are included in the article's Creative Commons licence, unless indicated otherwise in a credit line to the material. If material is not included in the article's Creative Commons licence and your intended use is not permitted by statutory regulation or exceeds the permitted use, you will need to obtain permission directly from the copyright holder. To view a copy of this licence, visit http://creativecommons .org/licenses/by/4.0/.

\section{References}

1. International Diabetes Federation (IDF) and Diabetes and Ramadan International Alliance (DAR) (2017) Diabetes and ramadan: practical guidelines. Diabetes Res Clin Pract 126:303-316

2. Salti I, Bernard E, Detournay B, Bianchi-Biscay M, Le Brigand C, Voinet C et al (2004) A population-based study of diabetes and its characteristics during the fasting month of Ramadan in 13 countries: results of the epidemiology of diabetes and Ramadan 1422/2001 (EPIDIAR) study. Diab Care 27(10):2306-2311

3. Loh HH, Lim LL, Loh HS, Yee A (2019) Safety of Ramadan fasting in young patients with type 1 diabetes: a systematic review and meta-analysis. J Diabetes Investig 10(6):1490-1501. https:// doi.org/10.1111/jdi.13054

4. Elbarbary NS (2016) Effectiveness of the low-glucose suspend feature of insulin pump during fasting during Ramadan in type 1 diabetes mellitus. Diabetes Metab Res Rev 32:623-633

5. Bradley C, Lewis KS (1990) Measures of psychological wellbeing and treatment satisfaction developed from the responses of people with tablet-treated diabetes. Diabet Med 7(5):445-451

Publisher's Note Springer Nature remains neutral with regard to jurisdictional claims in published maps and institutional affiliations. 